\title{
Pioneering Project Planning Strategy: An Integration of Agile and Six Sigma
}

\author{
Erica \\ M.tech, \\ Department of Computer Science \& Engineering \\ Institute of Technology \& Management University
}

\author{
Sujata \\ Assistant Professor, Department of Computer \\ Science \& Engineering \\ Institute of Technology \& Management University
}

\begin{abstract}
When the software projects are developed, in earlier years, many of these projects fails or dropped because of not completion of projects. To resolve these problems and to provide the on-time delivery of project, an effective project plan is required along with project schedule. The project scheduling is effective to achieve the maximum benefit of available resources as well as to control the project cost and release. The problems associated with the system includes
\end{abstract}

- One of the major problems in software project management and scheduling is the estimation different resources associated with software development. These resources include the human and non-human analysis.

- $\quad$ The analysis over these parameters is defined under the constraint specification. These constraints here define the cost and benefit analysis.

There are numerous software those are working on planning and evaluation phase of software project development. AGILE is also one of them, famous for its customer oriented interaction based change adapting approach for delivering high-quality software and is tailored for its incremental and iterative characters. Talking about extreme programming, its ideology helps in reduction of defects and deals with changing customer requirements effectively. Whereas scope of improvement is still prevails and can be filled with the integration of both extreme programming and six sigma approaches. This paper elaborates importance of integrating six sigma and extreme programming for creating an automated work schedule system. Other products may solve the same cause but still lacks behind in accuracy and automation concept which is highlighted in this paper. Together Six Sigma and Agile will link organization strategy and business requirements via data driven mapping of processes and product and will one day take over the world in each and every field. It is believed that the reader of this paper has a prior knowledge of both six sigma and extreme programming.

\section{Keywords}

Agile Software Development, Six sigma, Extreme Programming

\section{INTRODUCTION}

This paper follows following order, section 1 includes about the history of various work scheduling systems and their failures along with that it tells about agile methodology, its plus points and some of its pain points as well. In section 2, limelight is on six sigma and its integration with extreme programming is there. Last but not the least, tentative model of work scheduling system is explained.

Software project management is the key approach that begins with the generation of project plan and continues till the software project delivery is not done. One of the key feature of this management project is the pre-analysis about the schedule or the order of execution of different activities associated with software projects. Software project scheduling actually presented a time frame analysis for each involved project activity as well as identify the effective delivery date for the software project. The key feature associated with software project development and deployment includes itself various associated concepts such as analysis over the human factors, non human factors, release versions, effectiveness of resource etc.

Software project management and the configuration would be done under the cost and reduction analysis so that the customer based software development would be done. If the software is developed for multiple versions then the estimation of the different version dates can also be done. The consideration is here defined in terms of associated constraints associated with the software projects. The software scheduling is not only effective to estimate the time for software release but it also gives multiple benefits. These benefits includes the estimation of project cost, software project criticality etc. The effectiveness of software system would be done under these defined constraints and associated deadlines. The presented work is focused on the same concept to obtain the software scheduling. The work has accepted different associated parameters to software project as input. These parameters are taken for human and non human factors along with their effectiveness. The estimation of the software project is also done under the effects of different releases. In this work, two main technologies of software management model are combined called agile based extreme programming approach and the six sigma model. The agile based extreme programming approach is effective to provide the automation over the work. This automation is about to identify the relationship between the software projects and relative resources. These resources and the utilization vectors are defined as the constraints under which the schedule is generated. The software project management and the effectiveness analysis and distribution between two different releases is managed under the six sigma framework. Based on this prior analysis, the estimation of software delivery date would be done. The release date estimation is performed under the concept of all the constraints and the benefits. The automated system is defined here that is tested for different task scenarios and based on it the results are obtained from the system.

\section{SUCCEEDING WITH AGILE}

Agile is one of the big buzzwords of the IT development industry.

\subsection{Key Principles of Agile Methodology}

There are mainly for core values of agile methodology mentioned in AGILE MANIFESTO from which the below mentioned key points are derived. Agile development can be a very stirring and revitalizing approach, apart from that many a project suits agile more than any other approach. The alliance and visibility will provide a much richer and more rewarding experience for teams to develop great software products. [6] 
1) Vital role of user involvement.

2) The team should be emancipated to make decisions.

3) Effectively handle emerging requirements in the static timeline.

4) Is lightweight and visual moreover handles most of the requirements at superior level.

5) Develop compact, phased releases and iterate.

6) Ensures time to time delivery of work assigned.

7) Design, development process, technical work, testing go hand in hand.

8) Testing is integrated throughout the project lifecycle - test early and often.

9) A collaborative \& cooperative approach between all stakeholders is essential.

10) Watchdogs should be there to check amount of work done to ensure its measurability.

\subsection{Extreme Programming(XP)}

Extreme Programming (XP) is no nonsense, code first approach to software delivery that emphasizes four basic activities: coding, testing, listening, and designing. Fast deliveries of product as people are fed up with 18 months delivery cycle that quite often deliver the wrong product. Idea of two week delivery cycles and quarterly release cadences is pretty appealing. It works on the below mentioned scenario:

1) You code because if you do not code, you will haven't done anything.

2) You test because if you don't test, you don't know when you are done coding.

3) You listen because if you don't listen you don't know what to code or what to test.

4) And you design so you can keep coding and testing and listening indefinitely.

It was the first agile method to truly challenge traditional Waterfall strategy. It stitched its own way apart from ethnic requirements tweeting up techniques, made testers vanguard of the delivery process, and brought into limelight the core software engineering practices like automated testing, refactoring, continuous integration (CI), and test-driven development (TDD).

\subsection{History Of Various Project Management Software}

Project management is similar to juggling a dozen balls at once. To complete a project successfully, we have to handle a large number of agitations ensuring there completion well before time. If you miss a deadline, it leads to dispersion for the rest of the project. Causing late delivery of the product and thus cost will rise. That's why it's mandatory to see and know what is to be done, what is done and to keep an eye on the target's dead line. There is a huge variety of project management applications out there. Mostly are general purpose apps which are not for any particular industry. Innovative applications geared up their features and are easily available, and some of their offerings are pretty good. Few examples are PERT chart and Gantt chart. They are probably the two best known charts in project management. Any of them can be brought into use for work scheduling. But have some or the other flaws like PERT is not easily scalable for minor projects. Generated charts are too large and unmanageable requires many large size papers. The non presence of a time interval on most PERT/CPM charts makes it harder to show status although colours can help. When the PERT/CPM charts becomes cumbersome, they are no longer used to manage the project.

\section{SIX SIGMA: STATISTICAL TOOL}

Six Sigma is a set of statistical tools that act as a lens through which hidden problems can be identified and root causes can be caught red handed. It acts as an equipment to think through tough issues. Also acts as a beam that provides the metrics required for reducing variability in process execution so as to enable on-going improvement in competitiveness and manufacturing and business operations. The name Six Sigma is actually a registered trademark of Motorola the innovator for the Six Sigma methods in the later nine teens. In recent times Motorola have symbolized the word in its own sexy way using the number six and the Greek sigma character.

\subsection{Pin points of six sigma}

There are various key points on which six sigma methodology work, they are as follows:

1) Critical to quality: Evaluates most important attributes from the customer's point of view.

2) Defect: Failing to deliver customer want.

3) Process Capability: Keep a note on your process capacity, what it can generate.

4) Variation: Customize the difference between what customer sees and feels.

5) Stable Operations: Safeguards regular, foreseeable process to improve.

6) Design for Six Sigma: Conceptualize to fulfill customer needs and ensures process capability.

\subsection{DMAIC process}

DMAIC is the part of Six Sigma methodology which is used as the standard routine for planning and implementation of project as shown in table 1 .

TABLE 1 DMAIC PROCESS [2]

\begin{tabular}{|l|l|}
\hline Steps & Key processes \\
\hline Define & $\begin{array}{l}\text { Define the requirements and expectations of the customer } \\
\text { Define the project boundaries } \\
\text { Define the process by mapping the business flow }\end{array}$ \\
\hline Measure & $\begin{array}{l}\text { Measure the process to satisfy customer's needs } \\
\text { Develop a data collection plan } \\
\text { Collect and compare data to determine issues and shortfalls }\end{array}$ \\
\hline Analyze & $\begin{array}{l}\text { Analyze the causes of defects and sources of variation } \\
\text { Determine the variations in the process } \\
\text { Prioritize opportunities for future improvement }\end{array}$ \\
\hline Improve & $\begin{array}{l}\text { Improve the process to eliminate variations } \\
\text { Develop creative alternatives and implement enhanced plan }\end{array}$ \\
\hline Control & $\begin{array}{l}\text { Control process variations to meet customer requirements } \\
\text { Develop a strategy to monitor and control the improved } \\
\text { process } \\
\text { Implement the improvements of systems and structures }\end{array}$ \\
\hline
\end{tabular}

\section{INTEGRATING EXTREME}

\section{PROGRAMMING AND SIX SIGMA}

Integrating six sigma with a software development process like extreme programming creates sustainable improvement in the 
development of the software and is an unbreakable management strategy. Applying six sigma in software development results in speedy integration and testing of the software. It also helps to create bug free software and it helps is more efficient program management. XP is famous as defect reduction technique and also deals with changing customer demands effectively. But the scope of falls can be removed by means of process improvement that is by involving six sigma. Using both together can provide a path to analyze data measurably and can map process management more effectively.

Still on having few odd beliefs both can be integrated and have following advantages:

1) Speeds up integration and tests.

2) Allow delivery of very high quality product.

3) Improves the repeatability and predictability of the entire software development process.

4) Use of statistical tools for real time analysis and decision support.

5) Quantifiable Software Process Improvement cost and benefits.

6) Controllable size, time and defects of a particular product.

7) Data is complete, consistent, and accurate.

8) Improvements are evaluated based on their impact on business goals, not maturity levels.

\section{TENTATIVE APPROACH}

\subsection{Problem Definition}

To develop a constructive software system, it is mandatory to define a software plan before designing the software. Software plan is helpful to find the answers of different research questions associated with the work. Software plan is an effective term used by management team to take the managerial decisions about the software system. Software plan is helpful to estimate the software cost and work schedule. The presented work is about to define an automated work schedule system inspired by extreme programming. The system will take the analytical decision about the process schedule under different vectors inspired from Six Sigma. The vectors considered here are mainly based on the requirement and the availability. The decision parameters considered here are number of human and non-human resources, capabilities of resources, utilization ratio etc. Once the information is retrieved, the next work is to implement the agile concept so that an automated task schedule under the project plan will be done. Finally, the result analysis will be done in the form of a Gantt chart.

\section{OBJECTIVE}

The presented system will cover the following research objectives:

1) Study of different Agile based approaches as well as detail study of Extreme programming approach.

2) Study of Six Sigma concept along with its integration to project analysis.

3) Identification of different parameters that will help to generate the project plan.

4) Applying the Agile based algorithm by using the contributions and availability as the training data set.
5) Design of a probabilistic algorithm to schedule the project modules under different project plan vectors.

6) Implementation of Work in user friendly environment using java.

\section{RESEARCH DESIGN}

Is shown below in table 2

TABLE 2WORK FLOW

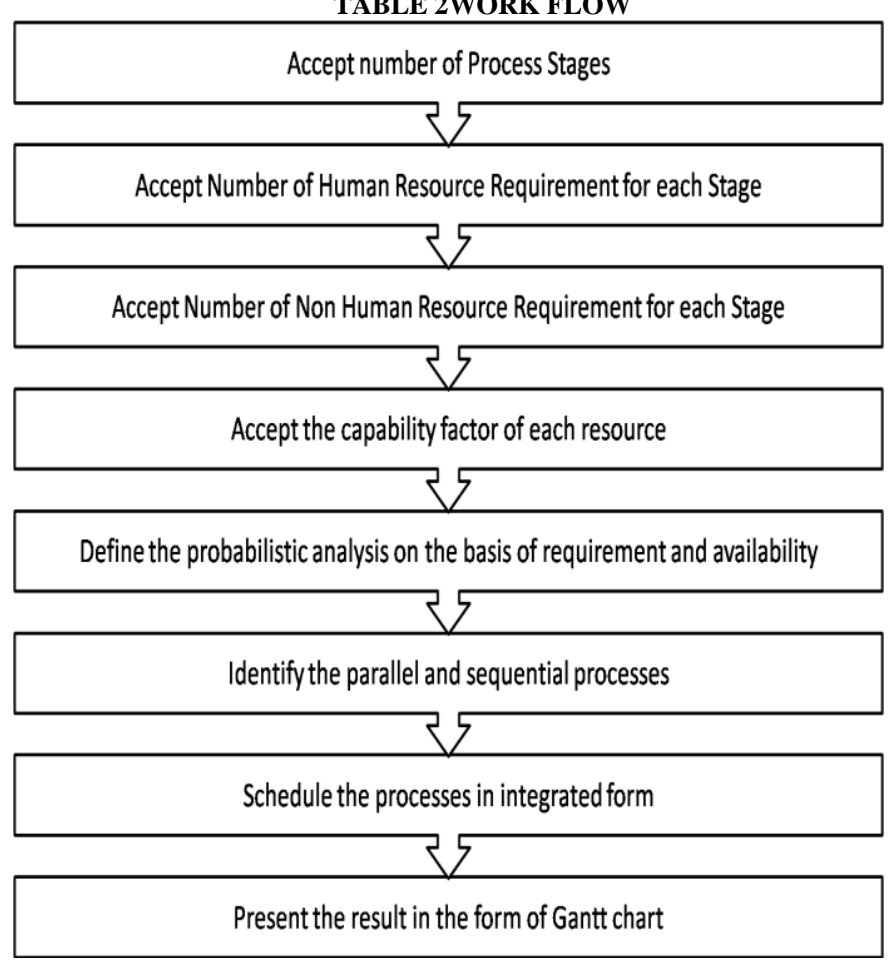

\section{RESULT}

To present the work on software release we need to pass input respective to the available resources and the strength of the software components. Here we have divided our work in four stages namely:

1) Input all non-human values. (As shown in table 3.)

2) Input all human values. (As shown in table 4.)

3) Generate initial solution.

4) Build optimal solution

5) Generate result in the form of Gantt chart. (As shown in figure 1.)

TABLE 3INPUT NON-HUMAN FEATURES

\begin{tabular}{|l|l|}
\hline & Parameters \\
\hline Number of Features & 5 \\
\hline $\begin{array}{l}\text { Number of Non Human } \\
\text { Resources }\end{array}$ & $10,5,12,6,18$ \\
\hline $\begin{array}{l}\text { Contribution in Development } \\
\text { (Release 1) }\end{array}$ & $4,5,3,5,2$ \\
\hline $\begin{array}{l}\text { Contribution in Development } \\
\text { (Release 2) }\end{array}$ & $3,5,3,4,1$ \\
\hline
\end{tabular}


TABLE 4INPUT HUMAN FEATURES

\begin{tabular}{|l|l|}
\hline & Parameters \\
\hline Number of Features & 5 \\
\hline $\begin{array}{l}\text { Number of Non Human } \\
\text { Resources }\end{array}$ & $10,5,12,6,18$ \\
\hline $\begin{array}{l}\text { Contribution in Development } \\
\text { (Release 1) }\end{array}$ & $4,5,3,5,2$ \\
\hline $\begin{array}{l}\text { Contribution in Development } \\
\text { (Release 2) }\end{array}$ & $3,5,3,4,1$ \\
\hline
\end{tabular}

On the basis of above data initial solution will be generated automatically using the concepts of extreme programming and further by applying the concepts of six sigma an optimal solution will be calculated. Further result will be generated in the form of the Gantt chart as shown below.

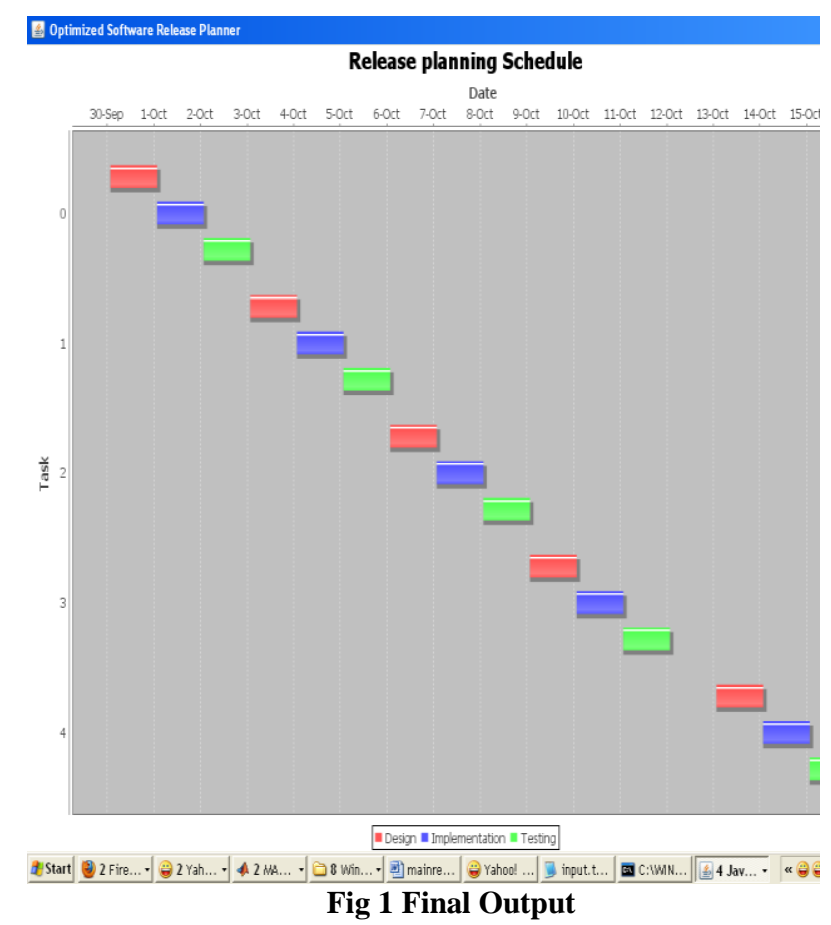

\section{REFERENCES}

[1] Jeffrey A. Livermore, Walsh College,jlivermore@walshcollege.edu,Factors that Impact implementing an Agile Software Development Methodology. IEEE Software.2007.

[2] YoungHoonKwak, Frank T. Anbari, "Benefits, obstacles, and future of six sigma approach," Technovation. Vol. 26, pp.708-715, 2006.

[3] Boehm, B. \& Turner, R. Management challenges to implement agile processes in traditional development organizations.IEEE Software. 22(5), 30-40. 2005.

[4] R. L. Glass, Software Runaways: Lessons Learned from Massive Software Project Failures.Upper Saddle River, NJ, USA: Prentice Hall, 1998

[5] R. L. Glass, Computingfailure.com: War Stories from the Electronic Revolution. UpperSaddle River, NJ, USA: Prentice Hall PTR, 2001.

[6] Beck, Kent; et al. (2001). "Principles behind the Agile Manifesto".Agile Alliance.Archived from the original on 14 June 2010.Retrieved 6 June 2010.

[7] Boehm, B. \& Turner, R. Management challenges to implement agile processes in traditional development organizations. IEEE Software. 22(5), 30-40. 2005.

[8] www.wikipedia.com. 